\title{
Viscoelastic Properties of Hyaluronan in Physiological
}

\section{Conditions [version 1; peer review: 2 approved]}

\author{
Mary K. Cowman¹, Tannin A. Schmidt ${ }^{2}$, Preeti Raghavan ${ }^{3}$, Antonio Stecco 4 \\ ${ }^{1}$ Biomatrix Research Center, Department of Chemical and Biomolecular Engineering, Polytechnic School of Engineering, New York \\ University, New York, NY, 10010, USA \\ ${ }^{2}$ Faculty of Kinesiology \& Schulich School of Engineering - Centre for Bioengineering Research \& Education, University of Calgary, \\ Calgary, AB, T2N 1N4, Canada \\ ${ }^{3}$ Department of Rehabilitation Medicine, Rusk Rehabilitation, New York University School of Medicine, New York, NY, 10016, USA \\ ${ }^{4}$ Department of Internal Medicine, University of Padova, Padua, 35100, Italy
}

V1 First published: 25 Aug 2015, 4:622
https://doi.org/10.12688/f1000research.6885.1

Latest published: 25 Aug 2015, 4:622

https://doi.org/10.12688/f1000research.6885.1

\begin{abstract}
Hyaluronan (HA) is a high molecular weight glycosaminoglycan of the extracellular matrix (ECM), which is particularly abundant in soft connective tissues. Solutions of HA can be highly viscous with nonNewtonian flow properties. These properties affect the movement of HA-containing fluid layers within and underlying the deep fascia. Changes in the concentration, molecular weight, or even covalent modification of HA in inflammatory conditions, as well as changes in binding interactions with other macromolecules, can have dramatic effects on the sliding movement of fascia. The high molecular weight and the semi-flexible chain of HA are key factors leading to the high viscosity of dilute solutions, and real HA solutions show additional nonideality and greatly increased viscosity due to mutual macromolecular crowding. The shear rate dependence of the viscosity, and the viscoelasticity of HA solutions, depend on the relaxation time of the molecule, which in turn depends on the HA concentration and molecular weight. Temperature can also have an effect on these properties. High viscosity can additionally affect the lubricating function of HA solutions. Immobility can increase the concentration of $\mathrm{HA}$, increase the viscosity, and reduce lubrication and gliding of the layers of connective tissue and muscle. Over time, these changes can alter both muscle structure and function. Inflammation can further increase the viscosity of HA-containing fluids if the HA is modified via covalent attachment of heavy chains derived from Intera-Inhibitor. Hyaluronidase hydrolyzes HA, thus reducing its molecular weight, lowering the viscosity of the extracellular matrix fluid and making outflow easier. It can also disrupt any aggregates or gel-like structures that result from HA being modified. Hyaluronidase is used medically primarily as a dispersion agent, but may also be useful in conditions where altered viscosity of the fascia is desired, such as in the treatment of muscle stiffness.
\end{abstract}

Open Peer Review

Approval Status

1

2

version 1

25 Aug 2015

$\checkmark$

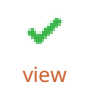

1. Timothy E. Hardingham, University of

Manchester, Manchester, UK

2. John Sandy, Rush University Medical Center, Chicago, USA

Anna Plaas, Rush University Medical Center, Chicago, USA

Any reports and responses or comments on the article can be found at the end of the article. 


\section{Keywords}

hyaluronan, viscosity, viscoelasticity, lubrication, fascia

This article is included in the Fascia research

collection.

Corresponding author: Mary K. Cowman (mary.cowman@nyu.edu)

Competing interests: No competing interests were disclosed.

Grant information: MC was supported in part by a grant from the Endre A. Balazs Foundation. TS, PR, and AS declared that no grants were involved in supporting their contributions.

The funders had no role in study design, data collection and analysis, decision to publish, or preparation of the manuscript.

Copyright: @ 2015 Cowman MK et al. This is an open access article distributed under the terms of the Creative Commons Attribution License, which permits unrestricted use, distribution, and reproduction in any medium, provided the original work is properly cited.

How to cite this article: Cowman MK, Schmidt TA, Raghavan P and Stecco A. Viscoelastic Properties of Hyaluronan in Physiological Conditions [version 1; peer review: 2 approved] F1000Research 2015, 4:622 https://doi.org/10.12688/f1000research.6885.1

First published: 25 Aug 2015, 4:622 https://doi.org/10.12688/f1000research.6885.1 


\section{Introduction}

Hyaluronan (HA) is a high molecular weight glycosaminoglycan polymer of the extracellular matrix (ECM) in vertebrate tissues ${ }^{1}$. It is composed of disaccharides of alternating D-glucuronic acid and $\mathrm{N}$-acetyl D-glucosamine connected by $\beta-1,3$ and $\beta-1,4$ glycosidic bonds, respectively. In most healthy tissues, HA has an average molecular weight of approximately 6-8 million ${ }^{2}$. HA has a high turnover rate, but homeostasis is normally maintained by similar rates of synthesis and degradation ${ }^{3,4}$. It can be enzymatically cleaved by hyaluronidases, or chemically degraded by hydroxyl radicals and peroxynitrite during inflammation ${ }^{5-7}$. It has a wide variety of physiological functions in the mammalian body, including maintenance of a viscoelastic cushion to protect tissues, control of tissue hydration and water transport, lubrication of biointerfaces, creation of large assemblies with proteins and proteoglycans in the ECM, and receptor-mediated signaling roles in cell detachment, mitosis, migration, tumor development, and inflammation ${ }^{3,8,9}$. HA is ubiquitous, but is particularly abundant in soft connective tissues, including between deep fascia and muscle, within muscle ${ }^{10-12}$, and also between the collagen layers that compose the deep fascia. This tissue is a multilayered structure formed by two to three layers of densely packed collagen fibers ${ }^{13,14}$, spaced by a layer of loose connective tissue (containing adipose cells, sulfated glycosaminoglycans and HA $)^{15-17}$. The proposed function of $\mathrm{HA}$ is to facilitate smooth gliding between these structures during movement, and in the transmission of force generated from muscle contraction.

The aim of the present study was to examine more closely the viscoelastic properties of HA in association with these structures, and to evaluate if the above mechanisms can be affected by HA viscoelastic variations.

\section{Review of the field}

Solutions of high molecular weight hyaluronan can be highly viscous with non-Newtonian flow properties (see for example the review by Cowman and Matsuoka ${ }^{18}$ and references therein). These properties may affect the movement of HA-containing fluid layers within and underlying the deep fascia. Additionally, the concentration and molecular weight of HA affects its contribution to the lubrication of biological interfaces. Changes in the concentration, molecular weight, or even covalent modification of HA in inflammatory conditions, as well as changes in binding interactions with other macromolecules, can have dramatic effects on the sliding movement of fascia.

\section{High molecular weight and the semi-flexible chain of $\mathrm{HA}$ are key factors leading to the high viscosity of dilute solutions}

For a semi-flexible polymer such as HA, the volume occupied by each chain is very large. Most of the volume is water, not bound by the polymer, and the polymer shape is constantly changing, but the water still contributes to the effective size of each molecule because the solvent movement is affected by frictional interaction with closely spaced polymer segments. Due to its rapid chain motions, the time-average shape of the molecule can be described as a sphere, with greatest density of chain segments near the center. Furthermore, the effective sphere-like volume of a wormlike HA chain in a good solvent grows approximately as the molecular weight raised to the power of $1.8\left(=\mathrm{M}^{1.8}\right)$. This means that, the larger the polymer, the lower the average density because the volume grows faster than the mass. For HA, with molecular weight normally in the millions, this leads to extremely large chain volumes. In contrast, the volume of a compactly folded globular protein chain increases only in direct proportion to the number of amino acids and is therefore proportional to the molecular weight to the first power. The expanded shape of a flexible polymer in solution is a key reason for the high viscosity of "unfolded" polymer solutions.

The hydrodynamic volume of HA chains is usually studied at an ionic strength that is close to physiological. At that ionic strength, the charges due to the carboxylate groups on the HA chain are almost completely screened from each other, and the repulsion between them does not significantly expand the coil volume. In solutions with lower salt concentrations than about $0.15 \mathrm{M} \mathrm{NaCl}$, the electrostatic repulsion would increase the hydrodynamic volume of individual HA molecules, and also increase repulsion between molecules.

The specific viscosity, $\eta_{s p}$, of an ideal polymer solution is proportional to the fraction of the solution volume that is filled with polymer chains. The Stokes-Einstein equation expresses the specific viscosity of a dilute solution of spherical particles (determined from the solution viscosity, $\eta$, and that of the pure solvent, $\eta_{0}$ ) as proportional to the product of the number of spherical particles per unit of solution volume, $n$, and the volumes of the particles themselves, $V$. This product corresponds to the volume occupied by all the particles, divided by the solution volume, or the volume fraction, $\phi$, of the solution that is occupied by particles. The occupied volume fraction can also be expressed in terms of the mass concentration of the polymer $\left(c\right.$, in $\mathrm{g}$ polymer $/ \mathrm{cm}^{3}$ of solution) multiplied by the specific volume of the polymer (in $\mathrm{cm}^{3}$ occupied/g). The specific volume (inverse of the density) is proportional to the intrinsic viscosity [ $\eta]$. As discussed above, the density of the polymer domain decreases with increasing molecular weight, so the intrinsic viscosity is a sensitive measure of the molecular weight. For HA in neutral aqueous salt solution at physiological ionic strength, the intrinsic viscosity is proportional to $\mathbf{M}^{0.819}$.

$\eta_{s p}=\frac{\eta-\eta_{0}}{\eta_{0}}=\frac{\eta}{\eta_{0}}-1=2.5 n V=2.5 \varphi=c[\eta]$ in dilute solution (1)

From Equation 1, we can see that the occupied volume fraction, $\phi$, is equal to $0.4 c[\eta]$. When the product $c[\eta]$ is 2.5 , the volume fraction is 1 , and the solution can be considered to reach the "coil overlap" point. This is the nominal point at which the chains fill the solution and are forced to touch each other, although they already interact at lower concentrations/hydrodynamic volumes, and can interpenetrate at higher concentrations/hydrodynamic volumes because the coil volumes contain mostly solvent. An ideal solution should be much more dilute than the critical concentration for coil overlap. Experimentally, the coil overlap point is usually identified as the value of $c[\eta]$ above which the specific viscosity begins to dramatically increase. 
In order to estimate the concentration at which a HA solution might exceed coil overlap, we can consider the hydrodynamic size of the polymer at different molecular weights (Figure 1$)^{20}$. Some example chain parameters are given below (Table 1$)^{20}$. For HA with a molecular weight of 6 million, overlap requires a HA concentration of only about $320 \mu \mathrm{g} / \mathrm{cm}^{3}(=2.5 / 7700)$. For HA with a molecular weight of 1 million, the coil overlap concentration would be about $1400 \mu \mathrm{g} / \mathrm{cm}^{3}$. For comparison, the concentration of HA in human synovial fluid is usually $2000-3000 \mu \mathrm{g} / \mathrm{ml}$, and the average molecular weight is close to 6 million, so the HA chains are well above the coil overlap point.

Based on the ideal model for HA in solution, specific viscosity should be equal to $c[\eta]$. A comparison of the observed behavior of HA solutions to the ideal case (Figure 2) shows that the ideal model is far from sufficient. Well below the coil overlap point of $c[\eta]=2.5$, HA solutions are already significantly non-ideal. Crowding between molecules increases the viscosity above that expected for the ideal solution.
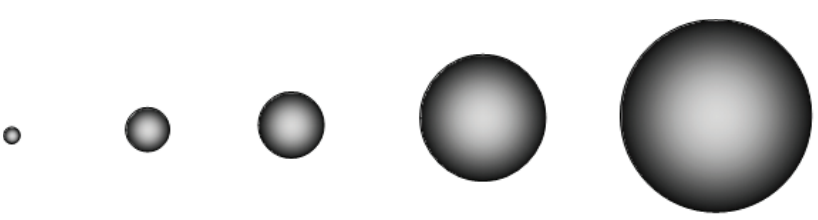

Figure 1. The hydrodynamic size of a hyaluronan chain depends on its molecular weight. Hyaluronan chains with molecular weight of (from left to right) 0.1, 0.5, 1, 3 and 6 million have hydrodynamic diameters of approximately 50, 140, 210, 400, and $600 \mathrm{~nm}$, respectively in physiological saline solution. The diameter of a small globular protein would be on the order of a few nm. Adapted from Cowman and Matsuoka ${ }^{20}$.

Table 1. Hydrodynamic size and intrinsic viscosity for hyaluronan of several different molecular weights, in physiological saline solution. The chain contour length, $L$, is calculated as $M / M_{L}$, where $M_{\perp}$ is the mass per unit length, approximately $401 \mathrm{~nm}^{-1}$, for the sodium salt form. The intrinsic viscosity of hyaluronan is related to $M$ by the equation $[\eta]=0.029 \mathrm{M}^{0.80}$. The specific volume of the polymer, $V_{s}$, was obtained from the intrinsic viscosity, as $[\eta] / 2.5$. Chain hydrodynamic diameter was approximated by the root mean square end-to-end distance, $\left\langle r^{2}\right\rangle^{1 / 2}$, of the polymer chain, which is equal to $([\eta] \mathrm{M} / \Phi)^{1 / 3}$, where $\Phi$ is the Flory constant with the empirical value of $2.1 \times 10^{23}$. Coil overlap concentration was calculated as $2.5 /[\eta]$, or equivalently, $1 / \mathrm{V}_{\mathrm{s}}$. Adapted from Cowman and Matsuoka ${ }^{20}$.

\begin{tabular}{|c|c|c|c|c|c|}
\hline M & $\begin{array}{l}L \\
(\mathrm{~nm})\end{array}$ & $\begin{array}{l}{[\eta]} \\
\mathbf{c m}^{3} / \mathbf{g}\end{array}$ & $\begin{array}{l}V_{s} \\
\mathrm{~cm}^{3} / \mathrm{g}\end{array}$ & $\begin{array}{l}<r^{2}>^{1 / 2} \\
(\mathrm{~nm})\end{array}$ & $\begin{array}{l}\text { c, for coil } \\
\text { overlap } \\
\left(\mu \mathrm{g} / \mathrm{cm}^{3}\right)\end{array}$ \\
\hline $1 \times 10^{5}$ & 250 & 290 & 120 & 52 & 8600 \\
\hline $5 \times 10^{5}$ & 1250 & 1100 & 420 & 140 & 2400 \\
\hline $1 \times 10^{6}$ & 2500 & 1800 & 730 & 210 & 1400 \\
\hline $3 \times 10^{6}$ & 7500 & 4400 & 1800 & 400 & 570 \\
\hline $6 \times 10^{6}$ & 15000 & 7700 & 3100 & 600 & 320 \\
\hline
\end{tabular}

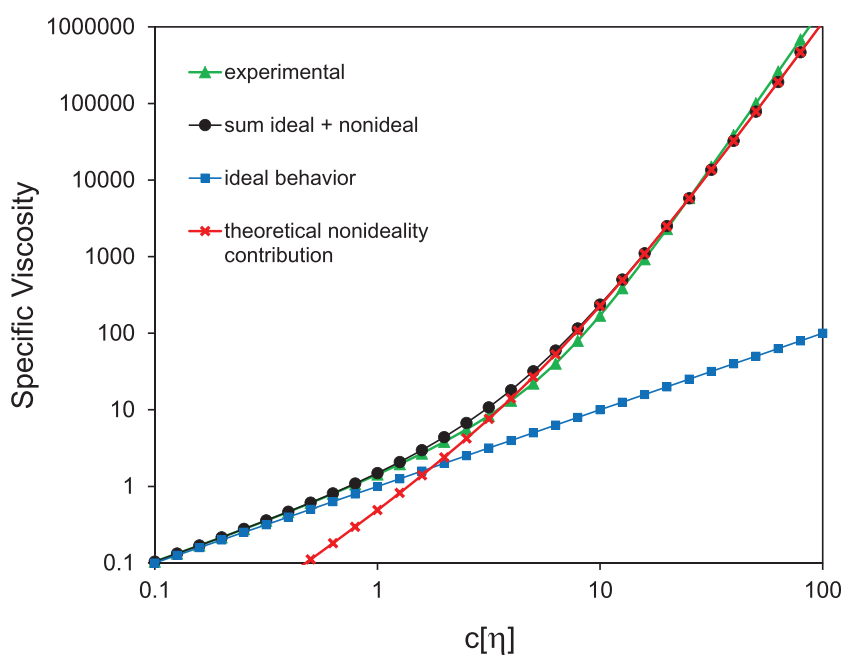

Figure 2. Specific viscosity of hyaluronan solutions, as a function of the concentration and intrinsic viscosity $[\eta]$. Experimental data for hyaluronan in physiological saline, plotted using the fitted equation $\eta_{s p}=c[\eta]+0.42(c[\eta])^{2}+7.77 \times 10^{-3}(c[\eta])^{4.18}$ reported by Berriaud and coworkers ${ }^{21}$, shows a marked increase in viscosity with increasing concentration and intrinsic viscosity. (Note that this data represents low shear conditions, where hyaluronan chains are not distorted or aligned with flow.) The experimental data can be compared with predictions based on theory. For an ideal case in which the hyaluronan molecules act independently, the specific viscosity would simply be equal to the product $c[\eta]$. When the molecules become crowded, the effective concentration increases, leading to a significant nonideality contribution, predicted by the last three terms of the mutual macromolecular crowding equation, (Equation 2 in text).

Real HA solutions show nonideality due to mutual macromolecular crowding, and greatly increased viscosity When polymer molecules in solution begin to restrict the space available for movement of other chains, the solution is no longer dilute, and our simple model needs modification. In Figure 2, a comparison of the curve from experimental data ${ }^{21}$ can be seen to deviate from the ideal case at values of $c[\eta]$ well below the nominal coil overlap point of 2.5 .

We have developed a theory for crowding between flexibly coiled macromolecules like $\mathrm{HA}^{18,22-24}$. It is based on the theory for gel filtration, developed by Ogston and Laurent ${ }^{25-27}$. The Ogston-Laurent theory for excluded volume provides a rational basis for understanding how proteins can be affected by a random suspension of fibers. A globular (spherical) protein is excluded from the space (a cylindrical shell) surrounding a fiber, by its own radius, and the thickness of the fiber. The center of the spherical protein defines its position, and the center cannot approach the fiber more closely than the sum of the radius of the sphere and the finite radius of the fiber. The probability of a protein finding space in a random suspension of such fibers (corresponding to the interior of a gel bead) is exponentially decreased as a function of the excluded volume. More fibers, or bigger proteins, mean less available space, and lower probability of being inside the beads. A similar picture can be imagined for the crowding of globular proteins by HA chains (Figure 3). 


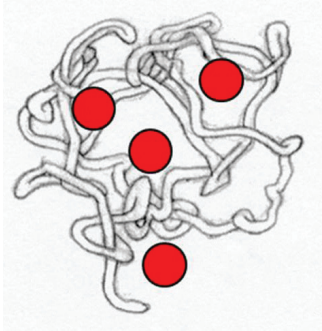

A

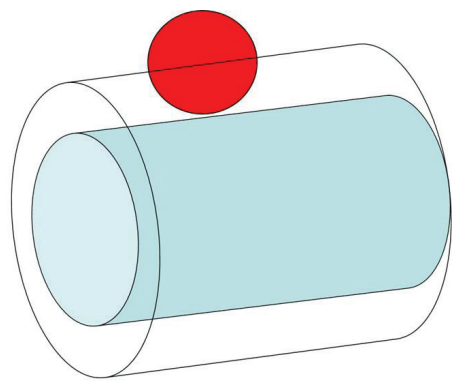

B
Figure 3. Model for steric exclusion of a globular protein by a hyaluronan molecule. A illustrates the ability of small globular proteins to penetrate most of the hydrodynamic domain of the hyaluronan polymer. B shows the size of the excluded volume for a globular protein in the presence of a segment of a linear polymer as a crowding agent. The cross section of the cylindrical excluded volume has a radius equal to the sum of the radius of the crowding polymer and the thickness of a cylindrical shell determined by the radius of the globular protein. This figure has been reproduced with permission from ${ }^{23}$ Cowman et al. (2012) in Structure and Function of Biomatrix. Control of Cell Behavior and Gene Expression. Ed. E.A. Balazs, pp.45-66. Copyright 2012 Matrix Biology Institute.

We adapted the Ogston-Laurent excluded volume concept to the problem of mutual exclusion (mutual macromolecular crowding) that occurs between coiled HA chains in solution. Each chain crowds the others, by an amount related to the hydrodynamic volume it occupies, rather than just its physical chain length and thickness (Figure 4).

The reduced probability of finding space for movement as a function of increased total concentration makes the effective concentration of the HA greater. The effective concentration is exponentially increased with HA real concentration and with the intrinsic viscosity. Since intrinsic viscosity is a measure of hydrodynamic volume, it is connected with molecular weight. The viscosity of HA solutions should then increase exponentially with concentration and molecular weight (as measured by intrinsic viscosity). We expanded the exponential term into a series. The first four terms of the series provide an excellent approximation of the observed specific viscosity. The first term is the ideal case, and the next three terms provide the nonideality contribution as shown in Figure 2. The sum of the two matches the experimental observation well ${ }^{18}$.

$$
\eta_{s p}=c[\eta]\left(1+k^{\prime} c[\eta]+\frac{\left(k^{\prime} c[\eta]\right)^{2}}{2 !}+\frac{\left(k^{\prime} c[\eta]\right)^{3}}{3 !}\right) \quad \mathrm{k}^{\prime}=0.4
$$

Now the extremely high viscosity of HA solutions can be successfully rationalized on the basis of mutual macromolecular crowding, which increases the effective concentration of the HA, and substantially increases the viscosity. There is no need to invoke intermolecular association or ordered structures of the HA molecules. It is

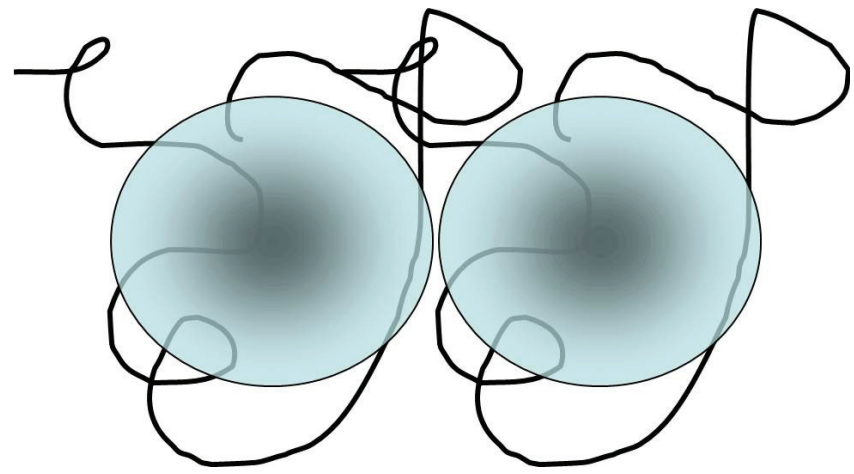

Figure 4. Model for mutual macromolecular crowding of hyaluronan molecules. The effective hydrodynamic domain of each chain is modeled as a sphere, the volume of which is dependent on the molecular weight to the 1.8 power. This figure has been reproduced with permission from ${ }^{23}$ Cowman et al. (2012) in Structure and Function of Biomatrix. Control of Cell behavior and Gene Expression. Ed. E.A. Balazs, pp.45-66. Copyright 2012 Matrix Biology Institute.

also of great interest to note that, depending on the starting point on the curve, increasing or decreasing the HA concentration or intrinsic viscosity (and thus molecular weight) can have enormous impact (e.g., varying as the third or fourth power of the change). The absence of ordered structures in pure semi-dilute HA solutions is also supported by HA diffusion coefficients measured by the confocal Fluorescence Recovery After Photobleaching (FRAP) studies of Hardingham and coworkers ${ }^{28,29}$.

\section{Effect of temperature and $\mathrm{pH}$ on the viscosity of hyaluronan solutions}

The large hydrodynamic volume of HA chains depends on the stiffness of the chain, which is due to steric hindrance to rotation about the linkages between sugar residues, and to the dynamically forming and breaking hydrogen bonds across those linkages. With increasing temperature, rotations about the linkages are easier, and the chains gain flexibility. This shrinks the molecular volume, and consequently reduces the viscosity. It is possible to predict the extent of viscosity reduction, based on Equation 2, and the known dependence of the intrinsic viscosity on temperature. Data from Cleland ${ }^{30}$ and Fouissac, Milas, and Rinaudo ${ }^{31}$ show that the intrinsic viscosity of high molecular weight HA is decreased by about $25 \%$ as the temperature is increased from $25^{\circ}$ to $65^{\circ} \mathrm{C}$. Hoefling et al..$^{32}$ showed that incorporating the $25 \%$ decrease in intrinsic viscosity into Equation 2 above gave an excellent prediction of the 2-3 fold experimental change in specific viscosity of semidilute HA solutions over that temperature range. There is no need to propose a change from an ordered conformation to a disordered one, because a modest increase in chain flexibility explains the marked solution viscosity change with temperature.

The viscosity of HA solutions is not very sensitive to $\mathrm{pH}$ in the physiological range. At very high $\mathrm{pH}$, above about $\mathrm{pH} 11$, the rotational freedom at the glycosidic linkages is greatly increased 
due to breakage of residual hydrogen bonds, and the chain volume shrinks, reducing the solution viscosity ${ }^{33-35}$. At low $\mathrm{pH}$ of about 2.5 , at physiological ionic strength, an interesting viscoelastic putty (nearly like a gel) is formed as a result of interchain association $^{33,35-37}$. But between $\mathrm{pH}$ values of 6.5-8.0, the expansion of the hyaluronan chains is nearly constant, and the intrinsic viscosity is not changed ${ }^{38}$.

The shear rate dependence of the viscosity, and the viscoelasticity of HA solutions, depend on the relaxation time of the molecule, while relaxation time depends on HA concentration and molecular weight

When a solution containing flexible polymers is flowing, the molecules can become distorted and stretched in the direction of the flow. The more slowly the molecules recover to their undisturbed shapes, relative to the rate of shear, the more they become aligned with the flow. The aligned molecules have a reduced contribution to the solution viscosity. In steady shear conditions, the solution viscosity is highest when the rate of shear is low, and molecules can reorient and relax to the undisturbed shape as rapidly as they move. But with increasing shear rate, the molecules cannot relax fast enough, and the viscosity drops. Figure 5 shows a typical example of the viscosity of a semi-dilute solution of HA in physiological solution $^{39}$.

This shear rate effect is seen for both dilute and semi-dilute solutions. In dilute solutions, the relaxation time depends on the molecular volume (proportional to the molar volume, $[\eta] M$ ) and the solvent viscosity. The more viscous the solvent, the longer the time needed for relaxation. In semi-dilute, or crowded solutions, the relaxation time is much more strongly increased because molecules must find space to move past each other. Again, the probability of finding space is exponentially related to the excluded volume. The higher the molecular weight, or the higher the concentration, the longer the relaxation time, and the more dramatic the loss of viscosity (shear thinning) with increasing shear rate ${ }^{18}$.

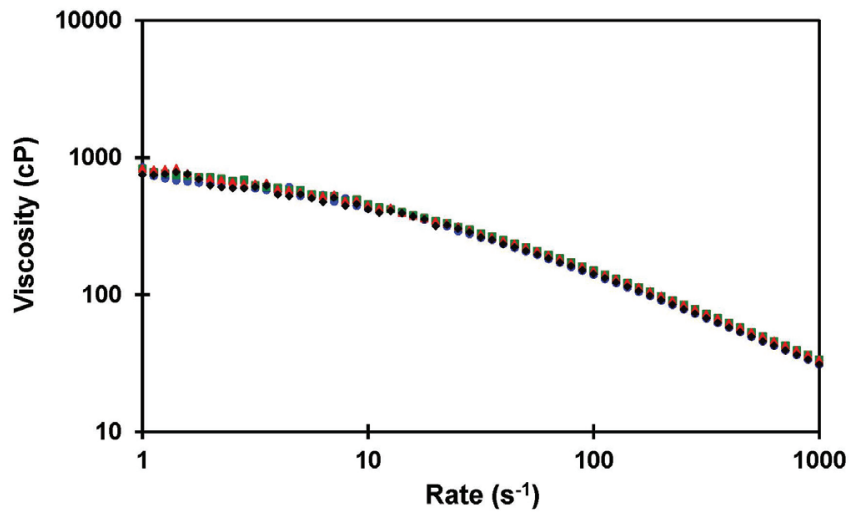

Figure 5. Shear rate dependence of the viscosity of a polydisperse hyaluronan sample (viscosity-average molecular weight $=1.7$ million) at a concentration of $5 \mathrm{mg} / \mathrm{ml}$ in PBS at $25^{\circ} \mathrm{C}$. Data from three consecutive runs are shown. This figure has been reproduced with permission from ${ }^{39}$ Cowman et al. (2011) Anal. Biochem., 417, 50-56. Copyright 2011 Elsevier Inc.
Another consequence of the long relaxation time of large HA molecules in semi-dilute solutions is a transition from viscous behavior to elastic behavior as a function of increasing rate of deformation (Figure 6$)^{40}$. If a solution is cyclically deformed, then slow rates allow the molecules to keep up with changes and flow. But rapid cyclic deformation does not allow the molecules to relax in shape, and instead they behave elastically, stretching and recoiling without flow. This behavior is called viscoelastic. For HA, it plays an important role in its protection of the articular joints under rapid motion. For HA in other tissues such as fascia, it can inhibit flow if the concentration and molecular weight are large enough that elastic behavior dominates under normal rates of motion.

\section{Effect of viscosity on lubricating function of HA solutions}

The three main modes of lubrication are boundary, fluid film or hydrodynamic, and mixed. In boundary mode lubrication, surfaceto-surface contact occurs between articulating surfaces, and molecules bound to the surface mediate friction. In fluid film lubrication, a thick (relative to the surface roughness of the articulating surfaces) viscous fluid film supports the load and separates the surfaces allowing motion with little resistance to shear. Mixed mode lubrication is where both boundary and fluid film mode lubrication are operative. The conditions under which each mode operate are classically defined by a Stribeck curve (Figure 7), which demonstrates how a friction coefficient $(\mu=$ friction force divided by normal force) varies with (velocity $\times$ viscosity/load $)^{41}$. Boundary mode lubrication occurs at the left end of the curve (low velocity and high loads with a small film thickness), whereas fluid film lubrication occurs at right end of the curve (high velocity and low loads with a

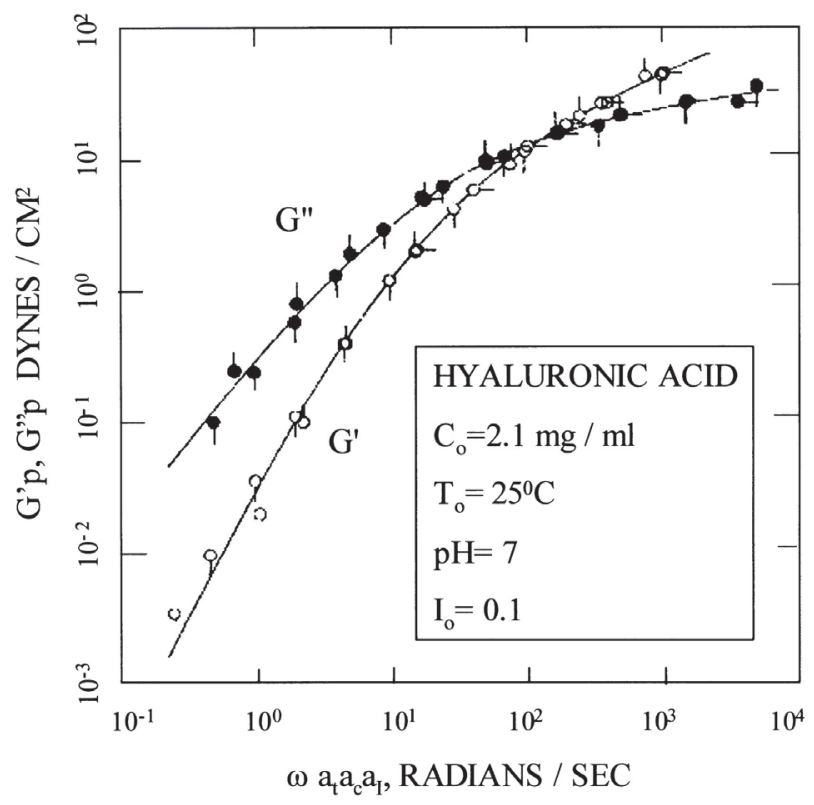

Figure 6. Master curves for the elastic modulus (G') and the viscous modulus (G") of a solution of HA with a molecular weight of $2.8 \times 10^{6}$ as a function of the frequency of displacement. This figure has been reproduced with permission from ${ }^{40}$ Gibbs et al. Biopolymers 1968, 6, 777-791. Copyright 1968 John Wiley \& Sons, Inc. 


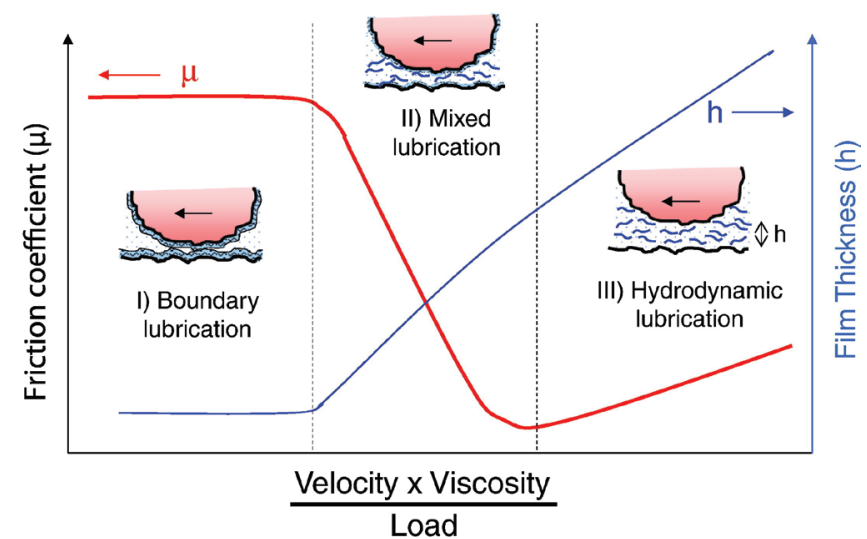

Figure 7. Friction coefficient plotted as a function of fluid viscosity and shear velocity divided by load (Stribeck curve) with corresponding lubrication film thickness. The schematic shows boundary, mixed, and hydrodynamic lubrication regimes. This figure has been reproduced with permission from ${ }^{41}$ Coles et al. (2010) Curr. Opin. Colloid Interface Sci. 15, 406-416. Copyright 2010 Elsevier Ltd.

large film thickness). While this curve was generated using classic hard, non-porous, engineering materials (e.g. steel), and may not be completely applicable to soft, porous, hydrated tissues or materials ${ }^{42}$, it is still useful in understanding general conditions under which different modes of lubrication are operative.

The viscosity of HA solutions can affect the mode of lubrication in which HA reduces friction as its relative effectiveness in reducing friction at tissue biointerfaces. For example, in a boundary mode of lubrication at a cartilage-cartilage biointerface, onto which HA is able to bind, relative effectiveness of friction reduction (especially static friction, the resistant to start up motion) has been shown to be dependent on the molecular weight of HA, with higher molecular weight resulting in lower friction (Figure 8$)^{43}$. This has been speculated to be due to a 'viscous boundary layer' of HA at the surface of cartilage ${ }^{44}$.

Conversely, in fluid film lubrication where a thick film of HA separates articulating surfaces, friction would be predicted to increase with viscosity, potentially reaching very high levels. In deep fascia, the thickness of the HA-containing fluid layer is apparently on the order of tens of microns, which is large compared with the diameter of the molecules and even the roughness of the surfaces. In such a case, if HA concentration and/or molecular weight are high, the resistance to flow due to high viscosity can negatively affect lubrication.

\section{Lubricin can decrease the viscosity of crowded high molecular weight hyaluronan solutions}

Lubricin is a lubricating mucin-like glycoprotein present in various body fluids, such as synovial fluid (essentially a $2-3 \mathrm{mg} / \mathrm{ml}$ solution of high molecular weight HA), that can alter the viscosity of HA solutions. We have shown that lubricin is able to reduce the
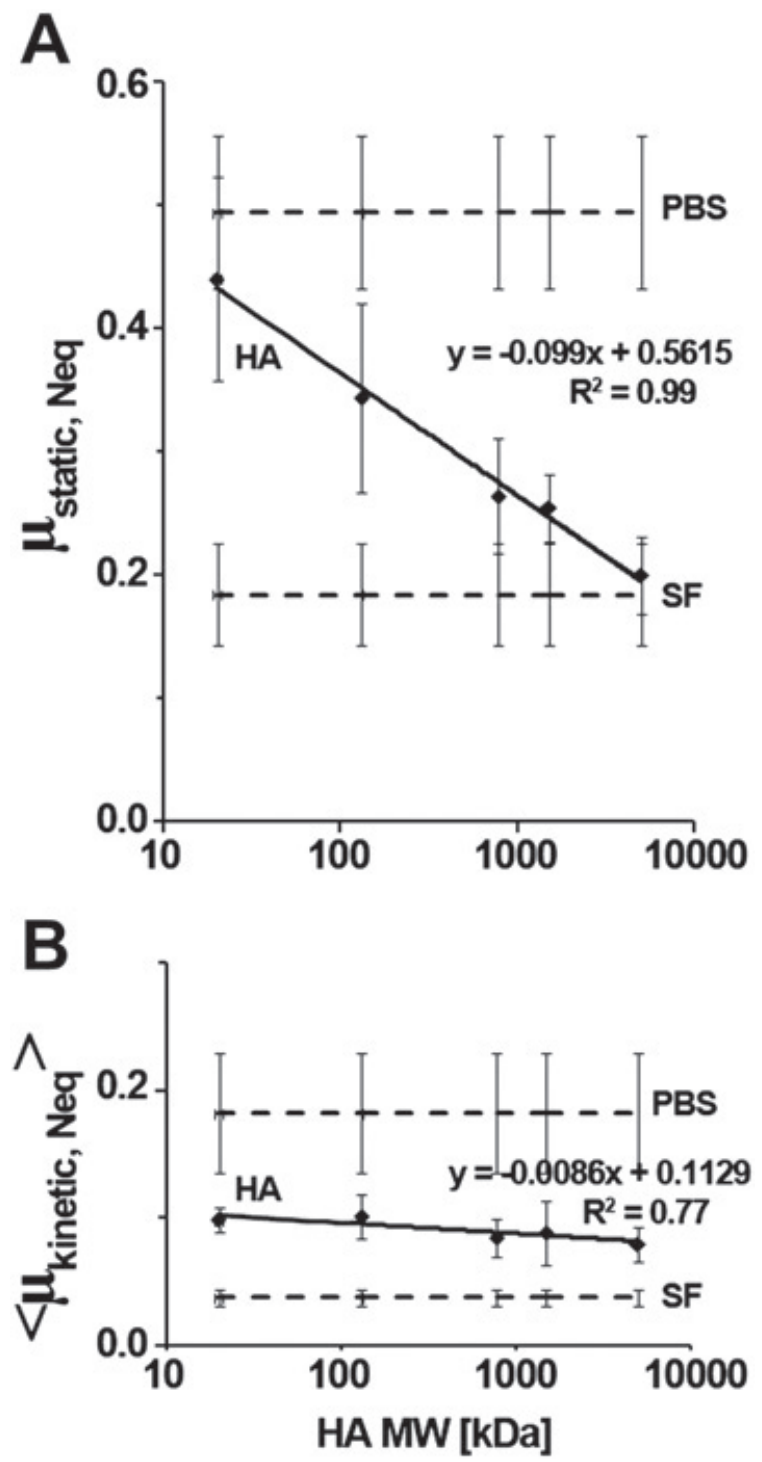

Figure 8. Dependence of the cartilage boundary lubricating properties of hyaluronan alone at $3.33 \mathrm{mg} / \mathrm{ml}$ on molecular weight. Regression lines are shown for $(\mathbf{A})$ mean static $\mu_{\text {static Neo }}$ friction values at pre-sliding duration, $T_{p s}=1,200 \mathrm{~s}$, and (B) mean kinetic $<\mu_{\text {kinetic Nee }}>$ friction values at $T_{p s}^{p s}=1.2 \mathrm{~s}$ obtained vs log molecular weight of hyaluronan. Mean values in phosphate-buffered saline (PBS) and synovial fluid (SF) are shown for reference. This figure has been reproduced with permission from ${ }^{43} \mathrm{Kwiecinski}^{\text {et }}$ al. (2011) Osteoarthritis Cartilage 19, 1356-1362. Copyright 2011 Osteoarthritis Research Society International.

viscosity of a high molecular weight HA solution when both components are present at physiological concentrations (Figure 9) ${ }^{45}$, potentially by binding and shrinking the hydrodynamic domains of HA molecules, enabling them to flow more easily. In cases where HA concentration becomes high and viscous flow is reduced, lubricin could facilitate increased motion and thus decreased friction. 
[HA] $=3.3 \mathrm{mg} / \mathrm{mL},[\mathrm{rhPRG} 4]=450 \mu \mathrm{g} / \mathrm{mL}, 25^{\circ} \mathrm{C}$

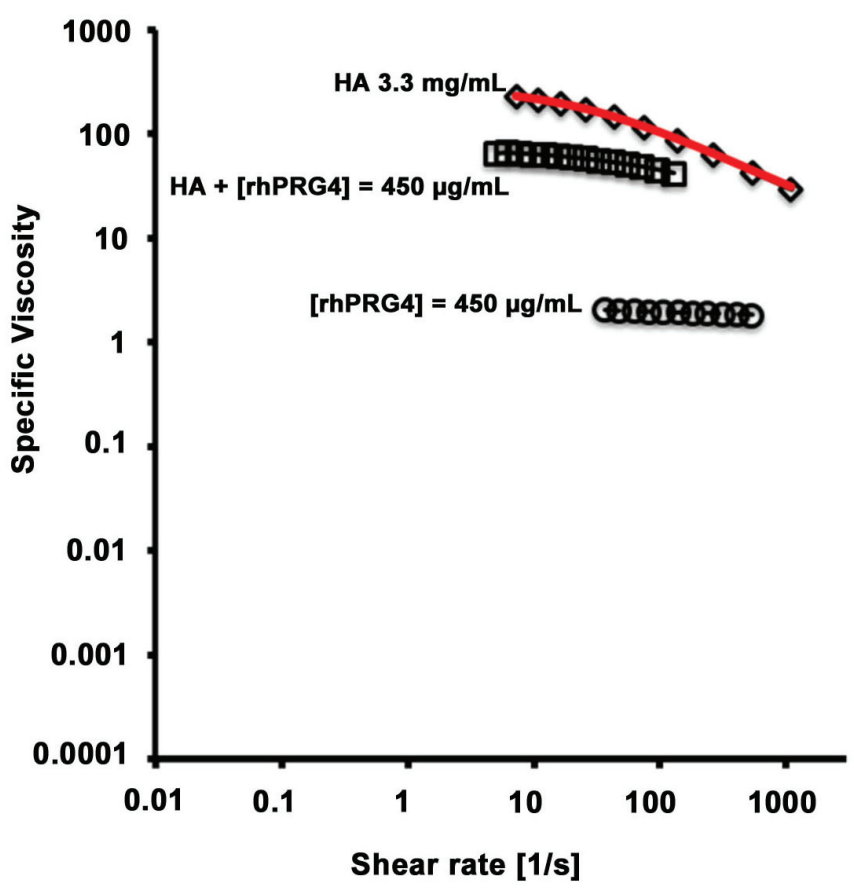

Figure 9. Lubricin (rhPRG4) can reduce the viscosity of HA (weight-average molecular weight of 1.5 million) solution when both are present at concentrations found in normal human synovial fluid. Shear rate dependent specific viscosity at $25^{\circ} \mathrm{C}$ of hyaluronan at $3.3 \mathrm{mg} / \mathrm{ml}$ alone and with $450 \mu \mathrm{g} / \mathrm{ml} \mathrm{rhPRG} 4$, shown in black. Predicted specific viscosity (experimental hyaluronan + experimental rhPRG4) shown in red. This figure has been reproduced with permission from ${ }^{45}$ Ludwig et al. (2014) Biorheology 51, 409-422. Copyright 2014 IOS Press and the authors.

HA is increased in concentration during inflammation, and can be covalently modified

A common observation in inflamed tissues is an increase in the concentration of $\mathrm{HA}^{2}$. The HA content of injured skeletal muscle is known to be elevated ${ }^{46}$. Stecco et $a l .{ }^{17}$ documented, with a highly specific HA-binding peptide, the deposition of HA inside the loose connective tissue in three different fasciae of the body: fascia lata, rectus abdominis sheet and sternocleidomastoid (SCM) fascia. Stecco et al. ${ }^{20}$ also documented an increase of the thickness of the loose connective tissue in the SCM fascia in patients complaining of chronic neck pain syndrome. If the HA content of fascia is increased, the viscosity and elasticity of the HA-containing fluid would be increased, and its fluid film lubricating properties reduced.

Possibly more important might be the covalent modification of HA by heavy chain domains derived from plasma inter- $\alpha$-inhibitor $(\mathrm{I} \alpha \mathrm{I})$. An increase in the expression of TSG-6 protein is commonly observed during inflammation. TSG-6 acts catalytically to transfer heavy chain (HC) domains from the chondroitin sulfate chain of I $\alpha \mathrm{I}$ to $\mathrm{HA}^{47-49}$. This transfer is normally a protective function that can stabilize the pericellular coat of cells. The HC domains can dimerize, and effectively act to hold HA chains noncovalently together ${ }^{50,51}$. It could be imagined that the HA, modified by HC, becomes gel-like and immobile in the deep fascia. HC-modified HA can also be found aggregated into fibers or cables ${ }^{52,53}$. An increase in both HA and TSG-6 has been reported in cultured vascular smooth muscle cells subjected to mechanical strain ${ }^{54}$, and proliferating smooth muscle cells in rat neointima after injury express high levels of TSG-6 ${ }^{55}$. Recently, an increase in HA, TSG-6, and HC-modified HA was observed in damaged mouse skeletal muscle tissue ${ }^{46}$.

\section{Discussion}

The fascia assumes a fundamental role with its two components: dense connective tissue (collagen fibers type I and III) and loose connective tissue (adipose cells, GAGs (glycosaminoglycans), and HA). HA is an important component of the loose connective tissue in fascia. In this review, we have considered the physico-chemical properties of HA solutions, and how they depend on factors such as concentration, molecular weight, and modification by covalent linkage to $\mathrm{HC}$ derived from I $\alpha \mathrm{I}$, or noncovalent interactions with proteins such as lubricin.

\section{Effect of immobility on concentration of $\mathrm{HA}$ and muscle structure}

Immobilization of a limb or body segment can lead to an increase in the concentration of HA within and between the fascial and muscular compartments, which can increase the fluid viscosity. The increased fluid viscosity within the loose connective tissue can in turn decrease the gliding between the layers of collagen fibers, which may be perceived by the subject as stiffness ${ }^{56}$. Changes documented in rat soleus muscle due to one week of immobilization include increase in HA concentration and shortening of sarcomere length ${ }^{57}$. These changes were postulated to increase the number of cross bridges attached during contraction ${ }^{58,59}$. In the early stages of this process, the arrangement of collagen fibrils in the endomysium may remain longitudinal, however, by about 4 weeks, the collagen fibrils became arranged circumferentially, which signals pre-contracture. Thus subtle changes in the turnover of HA and in the properties of the extracellular matrix with immobility can lead to structural and eventually functional changes in the muscles with significant consequences on movement ${ }^{60}$.

The interdependence of mechanoreceptor activation and viscoelasticity of the surrounding tissue has been previously noted ${ }^{61-65}$. Due to the fundamental role of HA in determining the viscoelasticity of fluids in soft connective tissues, its alteration could therefore modify the activation of the receptors, producing non-specific musculoskeletal pain.

The increased HA content of fascia and the underlying muscle may result from increased HA synthesis, due to a stimulation of the fibroblast-like cells that were previously suggested to be the biosynthetic source of hyaluronan ${ }^{17}$. It may also reflect impaired turnover via flow toward the lymph. A high HA concentration would increase the viscosity of the HA-containing fluids. When the viscosity of the fluid in the loose connective tissue increases due to increased HA concentration or its covalent modification, the dense connective tissue can spread the stiffness throughout the surrounding areas, driving even further the sensation of muscle stiffness. 
Deep friction manipulation may aid outflow of HA if the effective shear rate within the fluid layers generates a drop in the viscosity. This may explain the reduced perception of stiffness that is reported by both therapist and patient during this manual treatment. This review suggests a basis for the typical finding in manual therapy: the more chronic is the stiffness, the higher the concentration of HA may be, and the greater the effort and time required for manual treatments ${ }^{65}$

\section{Effect of hyaluronidase on $\mathrm{HA}$}

There are a number of HA-cleaving enzymes ${ }^{6}$. For medical applications, a preparation containing a recombinant fragment of human PH20 hyaluronidase is currently available. It hydrolyzes HA (and susceptible linkages in chondroitin sulfate glycosaminoglycans) by splitting the glycosidic bond between $\mathrm{C} 1$ of an $\mathrm{N}$-acetylhexosamine moiety and $\mathrm{C} 4$ of a glucuronic acid moiety. It reduces the molecular weight, and would be expected to lower the viscosity of the extracellular matrix fluid and thus make outflow easier. It can also disrupt aggregates or gel made by HA crosslinked via HC chains. The products of enzymatic cleavage may include small oligosaccharides of HA, which have been reported to trigger specific inflammatory responses and have a pro-inflammatory effect ${ }^{66,67}$. That possibility has been disputed ${ }^{68}$. In any case, the presence of fragments generated by the action of hyaluronidase is expected to be short lived as restored flow can wash the small polymers away. Hyaluronidase is used primarily as a dispersion agent, but may now be considered for use in conditions where altered viscosity of the fascia is desired, such as in muscle stiffness.

\section{Conclusion}

The physico-chemical properties of HA are modulated by its concentration, molecular weight, solvent ionic composition, temperature, and covalent or noncovalent binding of proteins and other species. If HA is forced to exist in a highly crowded environment, or more generally if its density within the loose connective tissue inside the fascia is increased as a result of injury or other pathological process, the behavior of the whole deep fascia and of the underlying connective tissue epimysium and perimysium could be compromised. Treatments that address the role of HA may hold promise.

\section{Author contributions}

MC, TS, PR and AS contributed to the writing of the manuscript. All authors have seen and agreed to the final content of the manuscript.

\section{Competing interests}

No competing interests were disclosed.

\section{Grant information}

MC was supported in part by a grant from the Endre A. Balazs Foundation. TS, PR, and AS declared that no grants were involved in supporting their contributions.

I confirm that the funders had no role in study design, data collection and analysis, decision to publish, or preparation of the manuscript.
1. Laurent TC, Fraser JR: Hyaluronan. FASEB J. 1992; 6(7): 2397-404. PubMed Abstract

2. Cowman MK, Lee HG, Schwertfeger KL, et al: The Content and Size of Hyaluronan in Biological Fluids and Tissues. Front Immunol. 2015; 6: 261. PubMed Abstract | Publisher Full Text | Free Full Text

3. Fraser JR, Laurent TC, Laurent UB: Hyaluronan: its nature, distribution, functions and turnover. J Intern Med. 1997; 242(1): 27-33. PubMed Abstract | Publisher Full Text

4. Tammi MI, Day AJ, Turley EA: Hyaluronan and homeostasis: a balancing act. J Biol Chem. 2002; 277(7): 4581-4 PubMed Abstract | Publisher Full Text

5. Li M, Rosenfeld L, Vilar RE, et al.: Degradation of hyaluronan by peroxynitrite. Arch Biochem Biophys. 1997; 341(2): 245-50. PubMed Abstract | Publisher Full Text

6. Stern R, Kogan G, Jedrzejas MJ, et al:: The many ways to cleave hyaluronan. Biotechnol Adv. 2007; 25(6): 537-57. PubMed Abstract | Publisher Full Text

7. Volpi N, Schiller N, Stern R, et al.: Role, metabolism, chemical modifications and applications of hyaluronan. Curr Med Chem. 2009; 16(14): 1718-45. PubMed Abstract | Publisher Full Text

8. Balazs EA: Viscoelastic properties of hyaluronic acid and biological lubrication. Univ Mich Med Cent J. 1968: 255-9. PubMed Abstract

9. Laurent TC, Laurent UB, Fraser JR: The structure and function of hyaluronan: An overview. Immunol Cell Biol. 1996; 74(2): A1-7. PubMed Abstract | Publisher Full Text

10. Piehl-Aulin K, Laurent $\mathrm{C}$, Engström-Laurent $\mathrm{A}$, et al:: Hyaluronan in human skeletal muscle of lower extremity: concentration, distribution, and effect of exercise. J Appl Physiol (1985). 1991; 71(6): 2493-8. PubMed Abstract

11. Laurent C, Johnson-Wells G, Hellström $\mathrm{S}$, et al:: Localization of hyaluronan in various muscular tissues. A morphological study in the rat. Cell Tissue Res.
1991; 263(2): 201-5

PubMed Abstract | Publisher Full Text

12. McCombe D, Brown T, Slavin J, et al:: The histochemical structure of the deep fascia and its structural response to surgery. $J$ Hand Surg Br. 2001; 26(2): 89-97.

PubMed Abstract | Publisher Full Text

13. Benetazzo L, Bizzego $\mathrm{A}$, De Caro $\mathrm{R}$, et al:: $3 \mathrm{D}$ reconstruction of the crural and thoracolumbar fasciae. Surg Radiol Anat. 2011; 33(10): 855-62. PubMed Abstract | Publisher Full Text

14. Lancerotto L, Stecco C, Macchi V, et al.: Layers of the abdominal wall: anatomical investigation of subcutaneous tissue and superficial fascia. Surg Radiol Anat. 2011; 33(10): 835-42. PubMed Abstract | Publisher Full Text

15. Stecco C, Porzionato A, Lancerotto L, et al.: Histological study of the deep fasciae of the limbs. J Bodyw Mov Ther. 2008; 12(3): 225-30. PubMed Abstract | Publisher Full Text

16. Stecco C, Pavan PG, Porzionato A, et al:: Mechanics of crural fascia: from anatomy to constitutive modelling. Surg Radiol Anat. 2009; 31(7): 523-9. PubMed Abstract | Publisher Full Text

17. Stecco C, Stern R, Porzionato A, et al:: Hyaluronan within fascia in the etiology of myofascial pain. Surg Radiol Anat. 2011; 33(10): 891-6. PubMed Abstract | Publisher Full Text

18. Cowman MK, Matsuoka S: Experimental approaches to hyaluronan structure. Carbohydr Res. 2005; 340(5): 791-809. PubMed Abstract | Publisher Full Text

19. Balazs EA: Amino sugar-containing macromolecules in the tissues of the eye and the ear. In The Amino Sugars: The Chemistry and Biology of Compound Containing Amino Sugars. EA Balazs, Jeanloz RW, Editor. Academic Press: New York, 1965; 401-460 Publisher Full Text

20. Cowman MK, Matsuoka S: The Intrinsic Viscosity of Hyaluronan. In Hyaluronan JF Kennedy, Phillips GO, Williams PA, Hascall VC, Editor. Woodhead Publishing 
Ltd. Cambridge, 2002; 75-78.

Publisher Full Text

21. Berriaud N, Milas M, Rinaudo M: Rheological study on mixtures of different molecular weight hyaluronates. Int J Biol Macromol. 1994; 16(3): 137-42. PubMed Abstract | Publisher Full Text

22. Matsuoka S, Cowman MK: Equation of state for polymer solution. Polymer. 2002; 43(12): 3447-3453.

Publisher Full Text

23. Cowman MK, Hernandez M, Kim JR, et al:: Macromolecular Crowding in the Biomatrix. In Structure and function of Biomatrix. Control of Cell Behavior and Gene Expression. EA Balazs, Editor. Matrix Biology Institute: Edgewater, NJ, 2012; 45-66.

24. Cowman MK, Mendichi R: Methods for Determination of Hyaluronan Molecular Weight. In Chemistry and Biology of Hyaluronan, HG Garg and CA Hales, Editors. Elsevier: Amsterdam, 2004; 41-69.

Publisher Full Text

25. Ogston AG: The Spaces in a Uniform Random Suspension of Fibres. Trans Faraday Soc. 1958; 54(11): 1754-1757.

Publisher Full Text

26. Laurent TC, Killander J: A theory of gel filtration and its experimental verification. J Chromatogr. 1964; 14(3): 317-330.

Publisher Full Text

27. Laurent TC: The interaction between polysaccharides and other macromolecules. 9. The exclusion of molecules from hyaluronic acid gels and solutions. Biochem J. 1964; 93(1): 106-12.

PubMed Abstract | Free Full Text

28. Gribbon P, Heng BC, Hardingham TE: The molecular basis of the solution properties of hyaluronan investigated by confocal fluorescence recovery after photobleaching. Biophys J. 1999; 77(4): 2210-6.

PubMed Abstract | Publisher Full Text | Free Full Text

29. Gribbon $\mathrm{P}$, Heng BC, Hardingham TE: The analysis of intermolecular interactions in concentrated hyaluronan solutions suggest no evidence for chain-chain association. Biochem J. 2000; 350(Pt 1): 329-35.

PubMed Abstract | Publisher Full Text | Free Full Text

30. Cleland RL: Effect of Temperature on the Limiting Viscosity Number of Hyaluronic Acid and Chondroitin 4-Sulfate. Biopolymers. 1979; 18(7): 1821-1828.

Publisher Full Text

31. Fouissac E, Milas M, Rinaudo M: Shear-rate, Concentration, Molecular Weight, and Temperature Viscosity Dependencies of Hyaluronate, a Wormlike Polyelectrolyte. Macromolecules. 1993; 26(25): 6945-6951. Publisher Full Text

32. Hoefling JM, Cowman MK, Matsuoka S, et al:: Temperature Effect on the Dynamic Rheological Characteristics of Hyaluronan, Hylan A and Synvisc ${ }^{\circledR}$. In Hyaluronan, JF Kennedy, Phillips GO, Williams PA, Hascall VC, Editor. Woodhead Publishing Ltd, Cambridge, 2002; 103-108.

Publisher Full Text

33. Morris ER, Rees DA, Welsh EJ: Conformation and dynamic interactions in hyaluronate solutions. J Mol Biol. 1980; 138(2): 383-400.

PubMed Abstract | Publisher Full Tex

34. Mathews MB, Decker $\mathrm{L}$ : Conformation of hyaluronate in neutral and alkaline solutions. Biochim Biophys Acta. 1977; 498(1): 259-63.

PubMed Abstract | Publisher Full Text

35. Gatej I, Popa M, Rinaudo M: Role of the $\mathrm{pH}$ on hyaluronan behavior in aqueous solution. Biomacromolecules. 2005; 6(1): 61-7. PubMed Abstract | Publisher Full Text

36. Pigman W, Hawkins W, Gramling E, et al:: Factors affecting the viscosity of hyaluronic acid and synovial fluid. Arch Biochem Biophys. 1960; 89: 184-93. PubMed Abstract | Publisher Full Text

37. Balazs EA: Sediment volume and viscoelastic behavior of hyaluronic acid solutions. Fed Proc. 1966; 25(6): 1817-22. PubMed Abstract

38. Balazs EA, Cowman MK, Briller SO, et al.: On the Limiting Viscosity Number of Hyaluronate in Potassium Phosphate Buffers Between pH 6.5 and 8. Biopolymers. 1983; 22(2): 589-591. Publisher Full Text

39. Cowman MK, Chen CC, Pandya M, et al:: Improved agarose gel electrophoresis method and molecular mass calculation for high molecular mass hyaluronan. Anal Biochem. 2011; 417(1): 50-6. PubMed Abstract | Publisher Full Text

40. Gibbs DA, Merrill EW, Smith KA, et al.: Rheology of hyaluronic acid. Biopolymers 1968; 6(6): 777-91.

PubMed Abstract | Publisher Full Tex

41. Coles JM, Chang DP, Zauscher S: Molecular mechanisms of aqueous boundary lubrication by mucinous glycoproteins. Curr Opin Colloid In Sci. 2010; 15(6): 406-416.

Publisher Full Text

42. Dunn AC, Sawyer WG, Angelini TE: Gemini Interfaces in Aqueous Lubrication with Hydrogels. Tribol Lett. 2014; 54(1): 59-66.

Publisher Full Text
43. Kwiecinski JJ, Dorosz SG, Ludwig TE, et al:: The effect of molecular weight on hyaluronan's cartilage boundary lubricating ability--alone and in combination with proteoglycan 4. Osteoarthritis Cartilage. 2011; 19(11): 1356-62. PubMed Abstract | Publisher Full Text

44. Yakubov GE, McColl J, Bongaerts $\mathrm{JH}$, et al:: Viscous boundary lubrication of hydrophobic surfaces by mucin. Langmuir. 2009; 25(4): 2313-21. PubMed Abstract | Publisher Full Text

45. Ludwig TE, Cowman MK, Jay GD, et al.: Effects of concentration and structure on proteoglycan 4 rheology and interaction with hyaluronan. Biorheology. 2014; 51(6): 409-22.

PubMed Abstract | Publisher Full Text

46. Torihashi S, Ho M, Kawakubo Y, et al:: Acute and Temporal Expression of TNF- $\alpha$-stimulated Gene 6 Product,TSG-6,in Mesenchymal Stem Cells Creates Microenvironments Required for Their Successul Transplantation into the Muscle Tissue. J Biol Chem. 2015.

PubMed Abstract | Publisher Full Text

47. Milner CM, Higman VA, Day AJ: TSG-6: a pluripotent inflammatory mediator? Biochem Soc Trans. 2006; 34(Pt 3): 446-50.

PubMed Abstract | Publisher Full Text

48. Sanggaard KW, Sonne-Schmidt CS, Krogager TP, et al:: TSG-6 transfers proteins between glycosaminoglycans via a $\mathrm{Ser}^{28}$-mediated covalent catalytic mechanism. J Biol Chem. 2008; 283(49): 33919-26. PubMed Abstract | Publisher Full Text | Free Full Text

49. Huang L, Yoneda M, Kimata K: A serum-derived hyaluronan-associated protein (SHAP) is the heavy chain of the inter alpha-trypsin inhibitor. $J$ Biol Chem. 1993; 268(35): 26725-30.

PubMed Abstract

50. Yingsung W, Zhuo L, Morgelin M, et al:: Molecular heterogeneity of the SHAP-hyaluronan complex. Isolation and characterization of the complex in synovial fluid from patients with rheumatoid arthritis. J Biol Chem. 2003; 278(35): 32710-8. PubMed Abstract | Publisher Full Text

51. He H, Li W, Tseng DY, et al.: Biochemical characterization and function of complexes formed by hyaluronan and the heavy chains of inter-alpha-inhibitor ( $\mathrm{HC}^{\star} \mathrm{HA}$ ) purified from extracts of human amniotic membrane. J Biol Chem. 2009; 284(30): 20136-46.

PubMed Abstract | Publisher Full Text | Free Full Text

52. de la Motte CA, Hascall VC, Drazba J, et al.: Mononuclear leukocytes bind to specific hyaluronan structures on colon mucosal smooth muscle cells treated with polyinosinic acid:polycytidylic acid: inter-alpha-trypsin inhibitor is crucia to structure and function. Am J Pathol. 2003; 163(1): 121-33. PubMed Abstract | Publisher Full Text | Free Full Text

53. Majors AK, Austin RC, de la Motte CA, et al.: Endoplasmic reticulum stress induces hyaluronan deposition and leukocyte adhesion. J Biol Chem. 2003; 278(47): 47223-31.

PubMed Abstract | Publisher Full Text

54. Lee RT, Yamamoto $C$, Feng $Y$, et al.: Mechanical strain induces specific changes in the synthesis and organization of proteoglycans by vascular smooth muscle cells. J Biol Chem. 2001; 276(17): 13847-51. PubMed Abstract | Publisher Full Text

55. Ye L, Mora R, Akhayani N, et al.: Growth factor and cytokine-regulated hyaluronan-binding protein TSG-6 is localized to the injury-induced rat neointima and confers enhanced growth in vascular smooth muscle cells. Circ Res. 1997; 81(3): 289-96.

PubMed Abstract | Publisher Full Text

56. Stecco A, Gesi M, Stecco C, et al.: Fascial components of the myofascial pain syndrome. Curr Pain Headache Rep. 2013; 17(8): 352.

PubMed Abstract | Publisher Full Text

57. Okita M, Yoshimura T, Nakano J, et al.: Effects of reduced joint mobility on sarcomere length, collagen fibril arrangement in the endomysium, and hyaluronan in rat soleus muscle. J Muscle Res Cell Motil. 2004; 25(2): 159-66.

PubMed Abstract | Publisher Full Text

58. Lieber RL, Steinman S, Barash IA, et al:: Structural and functional changes in spastic skeletal muscle. Muscle Nerve. 2004; 29(5): 615-27.

PubMed Abstract | Publisher Full Text

59. Julian FJ, Morgan DL: Tension, stiffness, unloaded shortening speed and potentiation of frog muscle fibres at sarcomere lengths below optimum. J Physiol. 1981; 319(1): 205-17.

PubMed Abstract | Publisher Full Text | Free Full Text

60. Stecco A, Stecco C, Raghavan P: Peripheral mechanisms contributing to spasticity and implications for treatment. Curr Phys Med Rehabil Rep. 2014; 2(2): 121-227.

Publisher Full Text

61. Song Z, Banks RW, Bewick GS: Modelling the mechanoreceptor's dynamic behaviour. J Anat. 2015; 227(2): 243-54. PubMed Abstract | Publisher Full Text

62. Bell J, Holmes $\mathrm{M}$ : Model of the dynamics of receptor potential in a mechanoreceptor. Math Biosci. 1992; 110(2): 139-74. PubMed Abstract | Publisher Full Text

63. Suslak TJ, Armstrong JD, Jarman AP: A general mathematical model of 
transduction events in mechano-sensory stretch receptors. Network. 2011; 22(1-4): 133-42.

PubMed Abstract

64. Loewenstein WR, Skalak R: Mechanical transmission in a Pacinian corpuscle. An analysis and a theory. $J$ Physiol. 1966; 182(2): 346-78.

PubMed Abstract | Publisher Full Text | Free Full Text

65. Swerup C, Rydqvist B: A mathematical model of the crustacean stretch receptor neuron. Biomechanics of the receptor muscle, mechanosensitive ion channels, and macrotransducer properties. J Neurophysiol. 1996; 76(4): 2211-20.

PubMed Abstract
66. Jiang D, Liang J, Noble PW: Hyaluronan as an immune regulator in human diseases. Physiol Rev. 2011; 91(1): 221-64.

PubMed Abstract | Publisher Full Text | Free Full Text

67. Stern R, Asari AA, Sugahara KN: Hyaluronan fragments: an information-rich system. Eur J Cell Biol. 2006; 85(8): 699-715.

PubMed Abstract | Publisher Full Text

68. Huang $\mathrm{Z}$, Zhao $\mathrm{C}$, Chen $\mathrm{Y}$, et al:: Recombinant human hyaluronidase PH20 does not stimulate an acute inflammatory response and inhibits

lipopolysaccharide-induced neutrophil recruitment in the air pouch model of inflammation. J Immunol. 2014; 192(11): 5285-95.

PubMed Abstract | Publisher Full Tex 


\title{
Open Peer Review
}

\section{Current Peer Review Status:}

\section{Version 1}

Reviewer Report 14 September 2015

https://doi.org/10.5256/f1000research.7412.r10133

(C) 2015 Sandy J et al. This is an open access peer review report distributed under the terms of the Creative Commons Attribution License, which permits unrestricted use, distribution, and reproduction in any medium, provided the original work is properly cited.

\author{
John Sandy \\ Department of Biochemistry, Rush University Medical Center , Chicago, IL, USA \\ Anna Plaas \\ Biochemistry, Internal Medicine, Rush University Medical Center, Chicago, IL, USA
}

This expertly constructed review article on hyaluronan (HA) provides an in-depth analysis of the relationship between its structural and physicochemical properties. The article also contains a well-informed update on the effects of modifications, such as protein binding, cross-linking and molecular weight on these properties. In particular, this is discussed in relation to its role in regulating the viscoelasticity of loose connective tissues (fascia) required for effective organ separation. For example, the authors point out that abnormally high HA-dependent viscosity in muscle fascia can lead to local and more generalized stiffness, and potentially mechanosensormediated pain. Indeed, this section could be expanded to underline the importance of future research on the effects of structural modifications on catabolic processing of HA, both within the extracellular matrix and in fluid compartments. On the general topic of hyaluronan-mediated effects at interfaces, readers will also find interesting the papers from Richter and colleagues who are examining the effects of end-grafted HA on the properties of glycoconjugate cell coats ( Richter, et al., 2007), lipid membranes (Attili, et al., 2012), nanoparticles (Bano, et al., 2015) and pulmonary surfactants (Lopez-Rodriguez, et al., 2013).

We have read this submission. We believe that we have an appropriate level of expertise to confirm that it is of an acceptable scientific standard. Competing Interests: No competing interests were disclosed.

Competing Interests: No competing interests were disclosed.

We confirm that we have read this submission and believe that we have an appropriate level of expertise to confirm that it is of an acceptable scientific standard.

Reviewer Report 02 September 2015 


\section{https://doi.org/10.5256/f1000research.7412.r10135}

(c) 2015 Hardingham T. This is an open access peer review report distributed under the terms of the Creative Commons Attribution License, which permits unrestricted use, distribution, and reproduction in any medium, provided the original work is properly cited.

\section{Timothy E. Hardingham}

Wellcome Trust Centre for Cell-Matrix Research, Faculty of Life Sciences, University of Manchester, Manchester, UK

This is an excellent review of the current biophysics and biology of hyaluronan. It presents an analysis of the complex non-ideal behaviour of hyaluronan characterised by different biophysical techniques and interprets this technical information in a way that enables the non-specialist to understand the consequences these properties have in biology. It's up to date and presents a very readable insight into the complex behaviour of this essentially simple biopolymer.

Competing Interests: No competing interests were disclosed.

I confirm that I have read this submission and believe that I have an appropriate level of expertise to confirm that it is of an acceptable scientific standard.

The benefits of publishing with F1000Research:

- Your article is published within days, with no editorial bias

- You can publish traditional articles, null/negative results, case reports, data notes and more

- The peer review process is transparent and collaborative

- Your article is indexed in PubMed after passing peer review

- Dedicated customer support at every stage

For pre-submission enquiries, contact research@f1000.com 